Prepared for the U.S. Department of Energy

under Contract DE-AC05-76RL01830

\title{
Building Diagnostic Market Deployment - Final Report
}

S Katipamula

N Gayeski

April 2012 


\title{
DISCLAIMER
}

This report was prepared as an account of work sponsored by an agency of the United States Government. Neither the United States Government nor any agency thereof, nor Battelle Memorial Institute, nor any of their employees, makes any warranty, express or implied, or assumes any legal liability or responsibility for the accuracy, completeness, or usefulness of any information, apparatus, product, or process disclosed, or represents that its use would not infringe privately owned rights. Reference herein to any specific commercial product. process, or service by trade name, trademark, manufacturer, or otherwise does not necessarily constitute or imply its endorsement, recommendation, or favoring by the United States Government or any agency thereof, or Battelle Memorial Institute. The views and opinions of authors expressed herein do not necessarily state or reflect those of the United States Government or any agency thereof.

\author{
PACIFIC NORTHWEST NATIONAL LABORATORY \\ operated by \\ BATTELE \\ for the \\ UNTIED STATES DEPARTMENT OF ENERGY \\ under Contract DE-AC05-76RLO1830 \\ Printed in the United States of America \\ Avaliable to DOE and DOE contractors from the \\ Office of Scientific and Technical Information, \\ P.O. Box 62, Oak Ridge, TN 37831-0062; \\ ph: (865) 576-8401 \\ fax: $(865) 576-5728$ \\ email: reports $a$ adonis.nsti.gov
}

\author{
Available to the public from the National Technical Information Service, \\ U.S. Department of Commerce, 5285 Port Royal Rd., Springfield, VA 22161 \\ ph: (800) 553-6847 \\ fax: (703) 605-6900 \\ email: orders $a$ ntis.fedworld.gov \\ online ordering: http:/www.ntis.gov/ordering.htm
}

This document was printed on recycled paper.

(9/2003) 
PNNL-21366

\section{Building Diagnostics Market Deployment - Final Report}

S Katipamula

N Gayeski ${ }^{(a)}$

April 2012

Prepared for

U.S. Department of Energy

under Contract DE-AC05-76RL01830

Pacific Northwest National Laboratory

Richland, Washington 99352

(a) KGS Buildings, LLC 



\section{Executive Summary}

Operational faults are pervasive across the commercial buildings sector, wasting energy and increasing energy costs by up to about 30\% (Mills 2009, Liu et al. 2003, Claridge et al. 2000, Katipamula and Brambley 2008, and Brambley and Katipamula 2009). Automated fault detection and diagnostic (AFDD) tools provide capabilities essential for detecting and correcting these problems and eliminating the associated energy waste and costs. The U.S. Department of Energy's (DOE) Building Technology Program (BTP) has previously invested in developing and testing of such diagnostic tools for whole-building (and major system) energy use, air handlers, chillers, cooling towers, chilled-water distribution systems, and boilers. These diagnostic processes can be used to make the commercial buildings more energy efficient.

The work described in this report was done as part of a Cooperative Research and Development Agreement (CRADA) between the U.S. Department of Energy's Pacific Northwest National Laboratory (PNNL) and KGS Building LLC (KGS). PNNL and KGS both believe that the widespread adoption of AFDD tools will result in significant reduction to energy and peak energy consumption. The report provides an introduction and summary of the various tasks performed under the CRADA. The CRADA project had three major focus areas: 1) Technical Assistance for Whole Building Energy Diagnostician (WBE) Commercialization, 2) Market Transfer of the Outdoor Air/Economizer Diagnostician (OAE), and 3) Development and Deployment of Automated Diagnostics to Improve Large Commercial Building Operations.

PNNL has previously developed two diagnostic tools: 1) whole building energy (WBE) diagnostician and 2) outdoor air/economizer (OAE) diagnostician. WBE diagnostician is currently licensed non-exclusively to one company. As part of this CRADA, PNNL developed implementation documentation and provided technical support to KGS to implement the tool into their software suite, Clockworks ${ }^{\mathrm{TM}}$. PNNL also provided validation data sets and the WBE software tool to validate the KGS implementation.

OAE diagnostician automatically detects and diagnoses problems with outdoor air ventilation and economizer operation for air handling units (AHUs) in commercial buildings using data available from building automation systems (BASs). As part of this CRADA, PNNL developed implementation documentation and provided technical support to KGS to implement the tool into their software suite. PNNL also provided validation data sets and the OAE software tool to validate the KGS implementation.

Finally, as part of this CRADA project, PNNL developed new processes to automate parts of the re-tuning process and transfer those process to KGS for integration into their software product. The transfer of DOE-funded technologies will transform the commercial buildings sector by making buildings more energy efficient and also reducing the carbon footprint from the buildings.

As part of the CRADA with PNNL, KGS implemented the whole building energy diagnostician, a portion of outdoor air economizer diagnostician and a number of measures that automate the identification of re-tuning measures. 


\section{Acknowledgments}

The authors would like to acknowledge the Buildings Technologies Program of the U.S. Department of Energy, Office of Energy Efficiency and Renewable Energy for supporting the research and development effort. The authors would also like to thank Alan Schroeder,

Technology Development Manager; George Hernandez (PNNL) for technical guidance; Danny Taasevigen for providing thoughtful technical review; Linda Sandahl (Program Manager at PNNL) for thoughtful comments and insights; Sue Arey for editorial support and Lorena Ruiz for administrative support in preparing the document. 


\section{Contents}

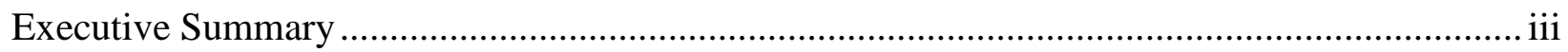

Acknowledgments......................................................................................................... iv

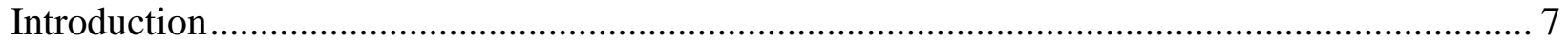

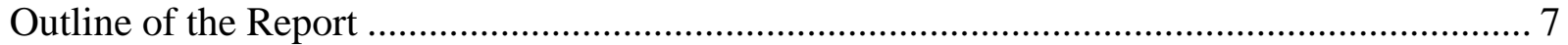

Summary of Market Transfer of the WBE Diagnostician .......................................................... 8

PNNL Contribution towards WBE Deployment ………………........................................ 8

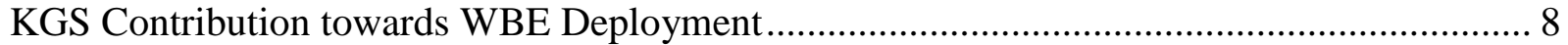

Preliminary User Feedback for WBE Diagnostic Deployment ............................................... 10

Summary of Market Transfer of the OAE Diagnostician...................................................... 12

PNNL Contribution towards OAE Deployment ............................................................. 12

KGS Contribution towards OAE Deployment ………….............................................. 12

Preliminary User Feedback for OAE Diagnostic Deployment.............................................. 14

Summary of Development and Deployment of Automated Diagnostics to Improve Large Commercial Building Operations .......................................................................................... 15

PNNL Contribution to Development Deployment of New Diagnostic Processes ................... 15

PNNL Contribution to Development Deployment of New Diagnostic Processes ................... 17

Preliminary User Feedback for New Diagnostic Process Deployment .................................... 20

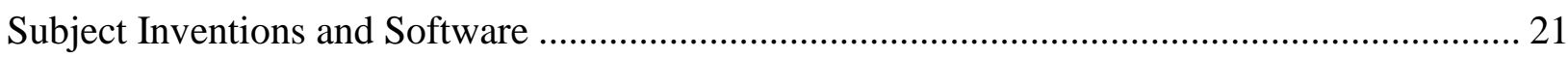

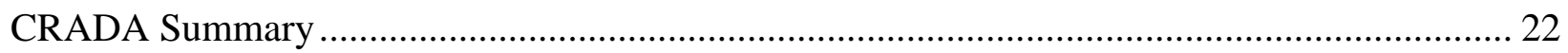

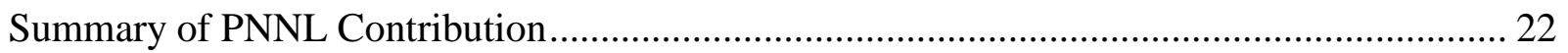

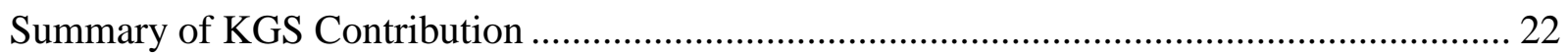

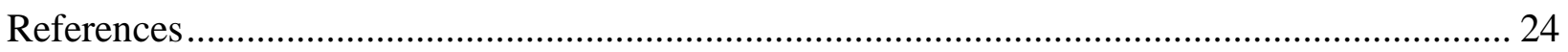




\section{Introduction}

Operational faults are pervasive across the commercial buildings sector, wasting energy and increasing energy costs by up to $30 \%$. Automated fault detection and diagnostic (AFDD) tools provide capabilities essential for detecting and correcting these problems and eliminating the associated energy waste and costs. The U.S. Department of Energy's (DOE) Building Technology Program (BTP) has previously invested in developing and testing such diagnostic tools for whole-building (and major system) energy use, air handlers, chillers, cooling towers, chilled-water distribution systems, and boilers. These diagnostic process can be used to make the commercial buildings more energy efficient.

Pacific Northwest National Laboratory (PNNL) and KGS Building LLC (KGS) both believe that the widespread adoption of AFDD tools will result in significant reduction to energy and peak energy consumption. KGS has developed a software product, Clockworks ${ }^{\mathrm{TM}}$, which is offered to customers as a software-as-a-service (SaaS). As part of this CRADA project, PNNL helped KGS integrate PNNL developed processes and tools into Clockworks. In addition, PNNL also provided documentation of the software, technical support, and help in testing and validation of KGS's implementation.

The CRADA project had three major focus areas: 1) Technical Assistance for Whole Building Energy Diagnostician (WBE) Commercialization, 2) Market Transfer of the Outdoor Air/Economizer Diagnostician (OAE), and 3) Development and Deployment of Automated Diagnostics to Improve Large Commercial Building Operations.

Automated diagnostics, including WBE, OAE and identification of re-tuning measures, are broadly applicable across many commercial building types, market segments, and types of equipment and systems. The greatest challenge in commercializing diagnostics for buildings is not developing the processes or rules, as discussed in this CRADA, but cost-effectively deploying diagnostics in a scalable way. The WBE, OAE and re-tuning diagnostics deployed during the CRADA are useful to building operators and managers, but only so far as they are willing, able and can afford to act on the diagnostic findings. Furthermore, the cost-effectiveness and scalability of diagnostics deployment depend on an infrastructure (Clockworks), which enables data collection, storage, and automation of diagnostics cheaply and replicably, all of which is outside the scope of the CRADA but important for context. Ultimately, the costs of gathering data, structuring data, deploying diagnostics, and interpreting diagnostics for building staff/service providers must be as low as possible so as not to prohibit commercializing the technology in large volume across many sites, even where the potential savings are small.

\section{Outline of the Report}

In the next section the detailed contributions from PNNL and KGS to implement WBE into KGS software suite are provided, followed by a section that provides details on PNNL and KGS contributions to implement OAE. The summary of development and deployment of automated diagnostics to improve large commercial building operations is also described. Finally, a section describing any new inventions or software development is provided, concluding with a section that summarizes the CRADA project. 


\section{Summary of Market Transfer of the WBE Diagnostician}

This section summarizes the contribution of PNNL and KGS in deployment of whole building energy (WBE) diagnostician into the Clockworks software suite.

\section{PNNL Contribution towards WBE Deployment}

WBE diagnostician was developed by PNNL and is currently licensed non-exclusively to one company. The software tool is written in ANSI C++ language and requires mysql database. The tool helps detect deviation of the actual energy consumption from the expected energy consumption. The deviation in energy consumption is detected by comparing actual to expected energy consumption. The expected energy consumption is computed using a baseline model based on the concept of data bins. A bin is an interval of values of an independent variable with which a value of another (dependent) variable is associated. More than one independent variable can be used to explain the variations in energy use. When multiple variables are used to explain the variations in energy use, multi-dimensional bins are used, where a multi-dimensional bin is defined as the intersection of one-dimensional bins based on each of the variables.

As part of this CRADA, PNNL helped KGS integrate WBE with Clockworks. PNNL created implementation documents and sample validation data sets. In addition to developing documentation, PNNL also provided ongoing technical support to help KGS integrate the diagnostic processes into Clockworks. The technical support was primarily by email, phone, and one in-person visit by PNNL to KGS.

\section{KGS Contribution towards WBE Deployment}

KGS has created new code to implement a modified WBE diagnostic algorithm based on the methods utilized in the WBE diagnostician. This code can be compiled and deployed through Clockworks and has been deployed in two test sites. The new code can be applied to any data point, which depends on a few independent variables for which training data exists.

Consequently, there are applications of this code across all building market segments for whole building utility meters, sub-meters, and equipment consumption monitoring. This code compares current consumption data with baseline training data, and then detects anomalous consumption. For any variable analyzed, Clockworks returns the Energy Consumption Index (ECI) (actual/expected consumption), the total actual consumption, the total expected consumption, and the expected consumption range. If the actual consumption over the analysis period is either higher or lower than the statistically significant expected range, an additional message is returned with the dollar equivalent of energy wasted or of energy saved.

The energy diagnostic compares whole-building or sub-metered energy consumption with a baseline model representing prior operating behavior. The baseline model is generated using a dynamic binning method and 2 to 12 months of historical data, typically at 5-minute intervals, similar to the WBE diagnostician binning methods. The historical data includes both independent variables (such as time of day and outdoor-air temperature) and the dependent variables to be analyzed (such as whole building electric power). Current and historical data are averaged over each hour before additional calculations are performed. 
For each hour of current data, bins of historical data are created dynamically based on similar independent variable values. In this way, current energy consumption is compared only to historical energy consumption that happened under similar conditions - for instance, one bin may include all electric power data collected between 10:00 a.m. and 11:00 a.m. within $\pm 2.5^{\circ} \mathrm{F}$ of the current day's 10:00 a.m. outdoor temperature. After a bin is created, the expected energy consumption can be generated for the given conditions, as well as a statistically significant expected consumption range, based on mean bias error (MBE) and root mean square error (RMSE). The total actual consumption divided by the total expected consumption is the ECI for that analysis period.

The supported independent and dependent variables are as follows:

Independent variables:

- Time of day/week

○ This variable can be binned by hour of the day, or hour of the week. Alternatively, this variable can be binned by hour of the day, but distinguishes between weekdays and weekend days.

- Outdoor-air temperature

$\circ$ This variable is binned using a temperature range around the current outdoor air temperature. The default bin is $\pm 2.5^{\circ} \mathrm{F}$, but this can be adjusted by building.

- Outdoor-air relative humidity $(\mathrm{RH})$

$\circ$ This variable is binned using a \% relative humidity range around the current outdoor air RH. The default bin is $\pm 5 \% \mathrm{RH}$, but this can be adjusted by building.

Dependent variables:

- Whole building electric power $(\mathrm{kW})$

- Sub-metered electric power $(\mathrm{kW})$

- Equipment power consumption $(\mathrm{kW})$

Outputs:

- Actual consumption over analysis period (in $\mathrm{kWh}$ )

- Expected consumption over analysis period (in $\mathrm{kWh}$ )

- Energy consumption Index (ECI)

$\circ \quad \mathrm{ECI}=($ Actual consumption $) /($ Expected consumption $)$

- Expected Range $=$ Expected consumption + sensitivity $x( \pm$ RMSE - MBE $) \times$ weight

- Text indicating main statistics and whether or not there was a COST or SAVINGS deviation

- Graphs showing the independent variables and the energy consumption with expected consumption ranges

KGS anticipates supporting many other utility consumption dependent variables, as necessary.

As mentioned above, Clockworks returns the ECI, actual consumption, expected consumption, expected consumption range, and cost impact of anomalies over the full analysis period (typically a day, a week, or a month). If there is a "high consumption" anomaly, Clockworks 
produces an energy and cost priority in proportion with user-defined price-points. Results can then be searched and organized by priority level and cost savings opportunity. In addition, Clockworks returns a time-series graph of the independent variables over the analysis period, as well as a time-series graph of the hourly (or daily) energy consumption for each dependent variable with the corresponding expected consumption limits. While the actual consumption may stray outside the expected limits at some point during the analysis period, the WBE does not recognize an anomaly unless the sum total actual consumption is outside the sum total expected consumption range.

KGS has deployed the WBE diagnostician on a couple of test sites: 1) using chiller power data from one client and 2) a building electric sub-meter from another. Approximately between 2 and 2.5 months of historical data was available for the baseline chiller power model, and approximately between 5 and 5.5 months of data was available for the electric sub-meter model.

In the chiller power examples, the independent variables were hour of the weekday/weekend and outdoor-air temperature $\left( \pm 2.5^{\circ} \mathrm{F}\right.$ bin size $)$. During one of the weeks tested, the chillers were found to use more power than expected given historical operation, and a cost of $\$ 93$ was calculated. The energy consumption index (ECI) - actual use divided by expected use - was 1.26. Looking more closely at one of the problem days during that week gives an ECI of 1.29 and an energy cost of $\$ 37$.

In the building electric sub-meter examples, the independent variables were the same as the chiller power example above. Several week-long periods and day-long periods were tested, and a few were found to deviate from the expected range. The historical data for this sub-meter is very uniform, so the expected range is significantly tighter in this example than it is in the previous example. Also, the total energy consumption is significantly greater than the previous example. Therefore, the days that deviate from historical values can have an ECI as low as 1.01 or 1.04 and a calculated energy cost in the hundreds of dollars. In this example, the expected range was possibly too tight, and we may change the sensitivity factor to avoid false positives.

\section{Preliminary User Feedback for WBE Diagnostic Deployment}

Four users at two sites were presented with the diagnostics results adapted from WBE methods. The diagnostic informs them, simply, when the whole building energy consumption, consumption through a sub-meter, or energy consumption via a piece of equipment deviates from the expected or baseline consumption based on a set of assumed independent variables. When deviations are found on past days, it is the job of the building operator or engineer to determine why the deviation occurred and assess what actions may be taken to correct it in the future. This analysis requires information external from the energy diagnostic, e.g., from operator knowledge or from other types of diagnostics, to enable the operator or engineer to assess other performance criteria co-occurring with the energy deviation. On its own and not in real-time, the energy diagnostic is of limited value. A real-time implementation of the energy diagnostic, which flags deviations while they are occurring, may provide operators the opportunity to attempt to correct energy performance on-the-fly, while it is deviating from expected.

One user felt the greatest utility would be in comparing the performance of systems before and after retrofits. Rather than searching for abnormal deviations from expected performance, the 
diagnostic would be used to validate that the retrofit system was performing better than a historical baseline based on pre-retrofit baseline data. 


\section{Summary of Market Transfer of the OAE Diagnostician}

This section summarizes the contribution of PNNL and KGS in deployment of outdoor air economizer (OAE) diagnostician into the Clockworks software suite.

\section{PNNL Contribution towards OAE Deployment}

OAE diagnostician is a diagnostic software tool that automatically detects and diagnoses problems with outdoor air ventilation and economizer operation for air handling units (AHUs) in commercial buildings using data available from building automation systems (BASs). The diagnostics tool can also be used on packaged rooftop units (RTUs). The software is written in ANSI C language and does not require any database product.

The software provides context-sensitive suggestions for correcting the problems detected. The diagnostics are based on rules derived from engineering models of proper and improper airhandler performance. These rules are implemented as a decision tree structure in the software. Data collected periodically from a BAS are used to navigate the decision tree and reach conclusions regarding the operating state of the AHU. Errors and uncertainty in measured data are handled through adjustable tolerance settings in the diagnostic software.

As part of this CRADA, PNNL helped KGS integrate OAE-related rules with Clockworks. PNNL created implementation documents and sample validation data sets. In addition to developing documentation, PNNL also provided ongoing technical support to help KGS integrate the diagnostic algorithm into Clockworks. The technical support was primarily by email, phone, and one in-person visit by PNNL to KGS.

\section{KGS Contribution towards OAE Deployment}

KGS has created new code to implement diagnostic algorithms for outdoor air economizers, which draws from the methodologies used in the OAE diagnostician. The economizer diagnostics in Clockworks primarily searches for sub-optimal or faulty economizer operation leading to wasted energy. Every night, analyses are run on data from AHU economizers to check for faults and inefficiencies. This diagnostic can be deployed to any AHU with an economizer, making it applicable to any building market segment with a pre-dominance of economizers, including large commercial office buildings, big box retail stores, and many other building types.

The economizer diagnostics implemented in Clockworks, like the OAE diagnostician, can handle four configurations of economizers, including:

- Enthalpy-based, differential control

- Enthalpy-based, high limit control

- Temperature-based, differential control

- Temperature-based, high limit control.

The economizer diagnostic performs the following steps, not in order, to determine whether the economizer is faulty or operating sub-optimally: 
- Calculates outdoor-air fraction from mixed, return and outdoor-air temperatures.

- Checks if too much outdoor air is being provided during the heating mode, and calculates wasted energy associated with excess heating.

- Checks if not enough outdoor air is being provided or if mechanical cooling is occurring during free cooling mode, and calculates wasted energy associated with excess cooling.

- Checks if not enough outdoor air is being provided during cooling mode, and calculates wasted energy associated with excess cooling.

- Checks if too much outdoor air is being provided during the mechanical cooling mode, and calculates wasted energy associated with excess cooling.

- Checks if outdoor-air damper is closed or partially open when it should be fully open.

- Checks if outdoor-air damper is partially or fully open when it should be closed.

- Checks for mechanical problems with outdoor air damper by checking correlation of damper position to outdoor-air fraction (OAF).

- Checks air flow measurements for consistency to look for flow reversals or sensor malfunctions.

- Check temperature sensor errors for the outdoor-, return-, mixed-, and discharge-air temperatures.

If any issues are found with the economizer based on these checks, graphs of the relevant variables (such as damper control positions, temperatures, air flow rates, OAF, or expected mode of operation) are generated (along with notes describing the issue found) and stored in Clockworks. Cost savings and an energy priority are assigned based on the calculated energy and cost wasted because of the fault.

KGS has deployed the economizer diagnostic on seven AHUs in two different buildings. Of the seven air handlers tested, two were found to have previously undetected problems and five were found to be operating correctly. Two examples of the faults identified by the Clockworks economizer diagnostic are discussed next.

In the first example, an AHU for which the wrong control program was loaded on to the controller and the dampers are varying according to a commissioning program rather than the economizer control. This is an error in the control sequence causing the economizer to not provide enough free cooling and operate at incorrect times. Clockworks automatically identified that the economizer was not properly operating based on outdoor air conditions, return air conditions and the control sequence and automatically flagged the issue when it occurred. Operators can take these graphs and notes generated by the software tool, download a PDF and attach them as information to work orders or distribute them to appropriate internal staff or external contractors. In this case, the work order led to reloading the correct control program for the economizer to fix the issue.

In the second example, an AHU for which the economizer OAF indicates that more free cooling is available than that provided by the economizer. In addition, the outdoor air damper is remaining closed when free cooling is available and mechanical cooling is occurring. This is causing the mixed air temperature set point to not be met. Furthermore, the mixed air temperature sensor has occasional faults, possibly a short to ground, and the OAF is too high when the outdoor-air damper is intended to be closed. The operators of this building have open 
work orders to replace the mixed air temperature sensor, correct any issues with the economizer control programming, and also investigate whether the outdoor air dampers are closing properly.

\section{Preliminary User Feedback for OAE Diagnostic Deployment}

Around 15 different users at two sites (covering 7 AHUs) have used the economizer diagnostic. They generally found the economizer diagnostic useful for quickly identifying when economizers are not operating as expected. Broken sensors, incorrect control programming, jammed dampers, broken actuators and various other problems regularly occur in economizers and are the cause of excess heating or cooling downstream on air handler coils. Users found it valuable to have Clockworks automatically flag that an economizer is broken, prioritize the problem relative to other issues, and provide a report that can be attached to work orders or shared with others.

Originally, the economizer diagnostic deployed in Clockworks included scatter plots of outdoor air temperature or enthalpy relative to OAF and other correlations; however, operators preferred to view simple time series plots of raw data from the control system instead. KGS has found that more data can be less information and lead to less action than simple, easily understandable data for the unfamiliar user. On the other hand, as users begin to understand the system more thoroughly, the additional graphics better illustrate performance. Part of the challenge in commercializing diagnostics for building energy efficiency is changing the culture of building management to accept data and graphical analysis as useful and productive tools and methods in managing buildings. 


\section{Summary of Development and Deployment of Automated Diagnostics to Improve Large Commercial Building Operations}

This section summarizes the contribution of PNNL and KGS in development and deployment of automated diagnostics to improve large commercial building operations and their integration into the Clockworks software suite.

\section{PNNL Contribution to Development Deployment of New Diagnostic Processes}

Today, many large commercial buildings use sophisticated BASs to manage a wide range of building equipment. While the capabilities of BASs have increased over time, many buildings still do not fully use their capabilities and are not properly commissioned, operated or maintained, which leads to inefficient operation, increased energy use, and reduced lifetimes of the equipment. "Tuning" building controls and heating, ventilation and air conditioning (HVAC) systems, much like tuning automobiles periodically, ensures maximum building energy efficiency and the comfort of building occupants. A poorly tuned system can and will maintain comfortable conditions but at a higher energy cost to overcome inefficiencies.

Periodic re-tuning of building controls and HVAC systems helps eliminate inefficient and faulty operations and improves building efficiency. Re-tuning, as it is practiced, is a systematic, semiautomated process of detecting, diagnosing and correcting operational problems with building systems and their controls. The focus of this process is to identify and correct building operational problems that lead to energy waste. The process is implemented primarily by leveraging data collected through BASs at little or no cost other than the labor required to make the necessary control changes. The focus of re-tuning is to identify and achieve significant energy savings at little cost; it might be thought of as a scaled-down retro-commissioning (RCx) process. The process has been shown to identify operational problems that can be corrected with low- or no-cost - and the impact is immediate. Unlike the traditional $\mathrm{RCx}$ approach, which has a broader scope, re-tuning primarily targets HVAC systems and their controls.

The goal of the joint work proposed as part of this CRADA is to transform the operations of HVAC systems in commercial buildings by implementing automated processes that can be deployed to re-tune BASs and the systems they control. These automated processes will make it easy to identify operational problems that require no- or low-cost to implement.

As part of this CRADA project, PNNL developed new processes to automate parts of the retuning process and transfer those processes to KGS for integration in their software product. The transfer of DOE-funded technologies will transform the commercial building sector by making buildings more energy efficient and also reducing the carbon footprint from the buildings.

As indicated previously, re-tuning focuses on identification and correction of operational problems. There are a number of operational problems that can be automatically detected on a continuous basis, including: 1) unscheduled operations of HVAC and lighting systems (running longer than needed); 2) improper economizer operations; 3) outdoor air intake not reset to zero (no ventilation) during morning warm-up or cool-down; 4) optimal start/stop not working properly; 5) reset of chilled and hot water not properly implemented; 6) higher static pressure 
than necessary to meet the building needs; 7) exhaust fans running all day $(24 \times 7) ; 8)$ faulty sensors; 9) improper set points; 10) improper control loop tuning; 11) variable speed equipment running at constant speed; 12) overrides of set points, dampers, valves, etc.; 13) simultaneous heating and cooling; and 14) excessive use of reheat. Based on the discussion with KGS, PNNL identified a list of measures for which the automated processes would be developed as part of the CRADA. The list included 12 categories of measures, and in some case, the categories had more than one sub-measure for which automated processes were developed. Therefore, a total of 30 processes were developed as part of this CRADA effort.

1. Problems indicated by trends in chiller distribution loop temperature difference (delta-T)

1.1. Chilled water loop delta-T (the difference between the return and supply water temperatures in the building/secondary loop) lower than the normal operating range.

2. Problems indicated by trends in boiler distribution loop temperature difference (delta-T) 2.1. Hot water loop delta-T (the difference between the supply and return water temperatures in the building loop) are lower than the normal operating range.

3. Opportunity for chilled or hot water temperature loop reset or better loop temperature set point

3.1. No chilled water loop supply temperature reset.

3.2. No hot water loop supply temperature reset.

3.3. High chilled water supply temperature set point.

3.4. Low chilled water supply temperature set point.

3.5. High hot water supply temperature set point.

4. Opportunity for water loop differential pressure (DP) reset

4.1. No chilled water loop DP reset.

4.2. No hot water loop DP reset.

4.3. High chilled water loop DP set point.

4.4. Low chilled water loop DP set point.

4.5. High hot water loop DP set point.

5. Lack of discharge air temperature reset and poor discharge air temperature set point

5.1. No discharge air temperature (DAT) reset schedule or the reset is disabled/overridden.

5.2. High DAT set point.

5.3. Low DAT set point.

6. High/low duct static pressure and lack of static pressure reset schedules

6.1. No duct static pressure reset.

aThe chilled water loop reset and hot water loop reset diagnostic process were separated because the configuration, threshold and tolerance could be different. 
6.2. High duct static pressure set point.

6.3. Low duct static pressure set point.

7. Excessive variable air volume (VAV) system reheat

7.1. Low discharge air temperature and majority of terminal units in heating mode.

8. Unscheduled or poorly scheduled HVAC and lighting equipment operation, such as continuous operation or operation during unoccupied periods

8.1. 24-hour or unoccupied period fan operation.

8.2. Unoccupied period chillers operation.

8.3. Unoccupied period boilers operation.

8.4. Unoccupied period lighting operation.

8.5. Any system that is ON during unoccupied period.

9. Improper control loop tuning, for valves, dampers, fan and pump speeds, etc.

9.1. Valve or damper controls hunting to meet set point.

9.2. Fan or pump speed control oscillation.

10. Faulty sensors

11. Detecting improper overrides of set points or actuators

11.1. Overridden control set points.

11.2. Overridden damper or valve actuators.

12. Excessive reheat at the zone terminal boxes.

Processes to automatically detect each re-tuning measure (fault) described in this section have been developed. Although the details of the processes are not presented in this report, each process includes the following details: 1) fault description, 2) input parameters required to implement the process, 3 ) description of the prerequisites for fault detection, 4) configuration parameters required to implement the process, 5) example charts showing the normal and "faulty" operation, 6) discussion of possible causes of the faulty operation, including opportunities for re-tuning and savings estimation methods and 7) flow charts showing input/output and configuration parameters showing the details of the process. It was assumed that the data required to identify the re-tuning opportunities will come automatically from the building automation system.

\section{PNNL Contribution to Development Deployment of New Diagnostic Processes}

KGS has created new code to implement diagnostic re-tuning processes, drawing from methodologies described by PNNL. This code has been deployed through Clockworks in seven test sites. The re-tuning diagnostics in Clockworks identify general faults or opportunities in major building systems such as chilled water loops, hot water loops, and variable air volume (VAV) systems, as well as in certain individual equipment. Because this set of processes 
considers a variety of systems, it can be used to assess any commercial building that is large enough to have central heating, cooling, or ventilation plant. The re-tuning diagnostics can be roughly divided into groups by plant or equipment, including cooling plant, heating plant, ventilation system, and general (miscellaneous equipment). Diagnostics in each of these categories have been implemented in Clockworks.

The cooling plant diagnostics implemented in Clockworks are primarily used to assess the chilled water loop. These diagnostics will:

- Determine if delta-T (return temperature minus supply temperature) across the chilled water loop is lower than the normal operating range.

- Determine if a chilled water supply temperature set point reset schedule based on outdoor-air temperature has been disabled or overridden.

- Determine if the chilled water supply temperature set point is too high or too low.

- Determine if a chilled water loop differential pressure set point reset schedule based on outdoor-air temperature has been disabled or overridden.

- Determine if the chilled water loop differential pressure set point is too high or too low.

- Determine if one or more chillers are running during unoccupied times of day.

The heating plant diagnostics implemented in Clockworks are primarily used to assess the hot water loop. These diagnostics will:

- Determine if delta-T (supply temperature minus return temperature) across the hot water loop is lower than the normal operating range.

- Determine if a hot water supply temperature set point reset schedule based on outdoor-air temperature has been disabled or overridden.

- Determine if the hot water supply temperature set point is too high.

- Determine if a hot water loop differential pressure set point reset schedule based on outdoor-air temperature has been disabled or overridden.

- Determine if the hot water loop differential pressure set point is too high.

- Determine if one or more boilers are running during unoccupied times of day.

The ventilation system diagnostics implemented in Clockworks are primarily used to assess general operations at the air handler level and in the VAV system. These diagnostics will:

- Determine if an air handler discharge-air temperature set point reset schedule based on outdoor air temperature has been disabled or overridden.

- Determine if the air handler discharge-air temperature set point is too high.

- Determine if there is excessive reheat at the zone terminal boxes due to low air handler discharge-air temperature.

- Determine if the air handler supply fans are running during unoccupied times of the day.

- Determine if a VAV system duct static pressure set point reset schedule based on outdoor air temperature has been disabled or overridden.

- Determine if the VAV system duct static pressure set point is too high. 
If any issues are found with a system or equipment based on the re-tuning diagnostics, Clockworks will generate a report with notes describing the issue found along with graphs of relevant variables such as temperatures, pressures, flows, control signals or valve positions. Clockworks will also graph or list major assumptions such as minimum or maximum thresholds and expected outdoor-air reset schedules. If the fault is associated with losses in energy (such as running chillers during unoccupied times), Clockworks will create cost savings and energy priorities based on the calculated energy and cost wasted because of the fault.

While the majority of the diagnostics processes implemented in Clockworks are similar to the faults described by PNNL, they were all modified to work within the Clockworks architectural framework. For example, most of the faults require a certain "window length" of data. These faults were modified to work within the Clockworks system, which is continuously collecting data. The Clockworks processes were also adjusted to have user-input thresholds (for example, minimum or maximum temperature thresholds) in addition to the suggested thresholds given by PNNL. In some cases, the Clockworks processes were expanded to be both more generic and to identify more specific faults than the original diagnostics processes. For example, the Clockworks processes for determining if an outdoor-air reset schedule for a discharge-air temperature has been overridden can accept a larger variety of data points than the original process, and it can compare the actual reset schedule to a known, expected reset schedule.

Some additional diagnostics developed by PNNL, which were not implemented in Clockworks. These include diagnostics for lighting controls and for identifying overridden control points. The lighting controls diagnostic was not implemented as a result of a lack of lighting control points in the building automation and controls systems (which Clockworks uses to obtain data). The processes for identifying overridden controls points were not implemented because they are typically visible within the building's control system and, therefore, it is not necessary to duplicate that information in Clockworks.

Re-tuning processes are currently deployed in seven buildings total, including 5 chilled water loops, 5 hot water loops, and 10 air handler and VAV systems. Of these, most were found to be operating correctly. Three examples of faults identified by Clockworks are described in this section: one for a chilled water loop, one for a hot water loop, and one for a ventilation system.

The graphs and results generated by KGS software can be downloaded or emailed as PDF files for use in work order systems or to be distributed to maintenance staff or contractors. The results also show a set of notes generated by Clockworks indicating the problem as well as either a list of possible causes or suggested actions. All results also include graphs that show the relevant information, including actual data and assumptions regarding thresholds and schedules, so the operator can easily see why the fault was flagged.

An example of a fault that KGS software detected included a chilled water loop for which the delta-T across the loop is too low. This occurred during times when the cooling load was low and indicated an opportunity for the operators to save energy by raising the chilled water supply temperature set point during times of low load, such as overnight. In this particular example, the "chiller running during unoccupied time" fault did not appear because the operators indicated to 
us that they would not consider turning off the chillers at night; however, turning off the chillers at night would also have resolved the problem and saved energy.

The second example of a fault that the software detected was a hot water loop with two issues: the hot water supply temperature set point is not following the expected outdoor-air reset schedule and the delta-T across the loop was too low. The reset schedule problem was found to be most likely because of a mechanical problem with the heat timer controller and may have partially contributed to the second issue, low delta-T. The low delta-T was also found to be partially the result of pump speeds that were programmed to be at the highest speed at all times.

The third example of a fault that the software detected was an air handler with two issues: the discharge air temperature set point is not following the expected outdoor-air reset schedule, and the discharge air temperature is too high. These two problems are related; it is clear from the graphs generated by Clockworks that the discharge air set points are much higher than the expected reset schedule. These problems are likely caused by an incorrectly programmed reset schedule.

\section{Preliminary User Feedback for New Diagnostic Process Deployment}

Over 30 Clockworks users representing seven buildings, including building operators, controls technicians, HVAC technicians, building managers, commissioning agents, and auditors had access to new re-tuning diagnostics. Re-tuning diagnostics were used to quickly assess whether systems were performing as expected. Some of the re-tuning diagnostics, for example identifying whether the static pressure set point was correct on a VAV system, required additional analysis from building engineers before operators were willing to make changes. This was particularly true for high risk buildings, such as laboratories, where adjustments to pressurization and air flows were of particular concern. However, once additional analyses were performed the user was very receptive to adjusting static pressure schedules to save energy.

Some diagnostics, such as low temperature differences on loops, were ignored based on limitations of the building systems. For example, if a plant was severely oversized for low partload operation or no variable speed drives were installed to adjust flows, there was little the operators and building owners were able or willing to do to re-tune the building. These types of diagnostics had to be disabled so that the automated re-tuning processes would not consistently show issues to which the owner was unwilling to respond.

Overall, user feedback about automated re-tuning processes has been very positive in that they are useful in identifying when systems are not performing well. However, the true cost of addressing any issues identified by the re-tuning diagnostics effect the perceived value of the retuning processes. A big hurdle to overcome is that many organizations are not structured to utilize tools like Clockworks to respond to diagnostics on building equipment. 


\section{Subject Inventions and Software}

None to report from either PNNL or KGS. 


\section{CRADA Summary}

The U.S. Department of Energy's (DOE) Building Technologies Program (BTP) and Federal Energy Management Program (FEMP) have supported the development, testing and deployment of algorithms and prototype diagnostic software at the Pacific Northwest National Laboratory (PNNL) over a number of years. One of the prototype diagnostic tools, the Whole Building Energy diagnostician, has been non-exclusively commercialized by one company. The other algorithms and prototype tools have not yet been commercialized but have been successfully tested and are ready for commercialization. As part of this CRADA project, PNNL provided implementation details of two software tools developed by PNNL to KGS for research purposes, and also helped develop additional diagnostic processes for incorporation into their product offering. If KGS commercializes the two tools developed by PNNL and also incorporates the new diagnostics processes into their service offering, it will transform the commercial building sector by making buildings more energy efficient and also reducing the carbon footprint from the buildings.

\section{Summary of PNNL Contribution}

PNNL has previously developed two diagnostic tools: 1) whole building energy (WBE) diagnostician and 2) outdoor air/economizer (OAE) diagnostician. The WBE diagnostician is currently licensed non-exclusively to one company. As part of this CRADA, PNNL developed implementation documentation and provided technical support to KGS to implement the tool into their software suite. PNNL also provided validation data sets and the WBE software tool to validate the KGS implementation.

The OAE diagnostician automatically detects and diagnoses problems with outdoor air ventilation and economizer operation for air handling units (AHUs) in commercial buildings using data available from building automation systems (BASs). As part of this CRADA, PNNL developed implementation documentation and provided technical support to KGS to implement economizer diagnostics into their software suite. PNNL also provided validation data sets and the OAE software tool to validate the KGS implementation.

Finally, as part of this CRADA project, PNNL developed new processes to automate parts of the re-tuning process and transferred those processes to KGS for integration into their software product. The transfer of DOE-funded technologies will transform the commercial building sector by making buildings more energy efficient and also by reducing the carbon footprint from the buildings.

\section{Summary of KGS Contribution}

As part of the CRADA with PNNL, KGS implemented the whole building energy diagnostic algorithms, components of the outdoor air economizer diagnostician algorithms, and a number of measures that automate the identification of re-tuning measures. 
KGS has created new code to implement a modified WBE diagnostic algorithm based on the methods utilized in the WBE diagnostician. This code can be compiled and deployed through Clockworks and has been deployed in two test sites. The new code can be applied to any data point that depends on a few independent variables for which training data exists.

KGS also has created new code to implement diagnostic algorithms for outdoor air economizers, which draws from the methodologies used in the OAE diagnostician. The economizer diagnostics in Clockworks primarily searches for sub-optimal or faulty economizer operation leading to wasted energy.

KGS has created new code to implement diagnostic re-tuning processes, drawing from methodologies described by PNNL. The re-tuning diagnostics in Clockworks identify general faults or opportunities in major building systems, such as chilled water loops, hot water loops, and VAV systems, as well as in certain individual equipment. 


\section{References}

Brambley, M.R., and S. Katipamula. 2009. "Commercial Building Re-tuning: A Low-Cost Approach to Improved Performance and Energy Efficiency." ASHRAE Journal, 51(10):12-23.

Claridge, D.E, C.H. Culp, M. Liu, S. Deng, W.D. Turner, and J.S. Haberl. 2000. "CampusWide Continuous Commissioning ${ }^{\text {SM }}$ of University Buildings." In Proceedings of the 2000 ACEEE Summer Study. Washington, D.C.: American Council for an Energy Efficient Economy.

Katipamula, S. and M.R. Brambley, "Transforming the Practices of Building Operation and Maintenance Professionals: A Washington State Pilot Program." 2008 ACEEE Summer Study on Energy Efficiency in Buildings Washington, DC: American Council for an Energy-Efficient Economy.

Liu, M, D.E. Claridge, and W.D. Turner. 2003. "Continuous Commissioning ${ }^{\text {SM }}$ of Building Energy Systems." ASME Journal of Solar Energy Engineering, Transactions of the ASME, Special Issue on Emerging Trends in Building Design, Diagnosis and Operation 125(3):275-281.

Mills, E. 2009. “A Golden Opportunity for Reducing Energy Costs and Greenhouse Gas Emissions.” http://cx.lbl.gov/2009-assessment.htm. Accessed on November 15, 2009. 


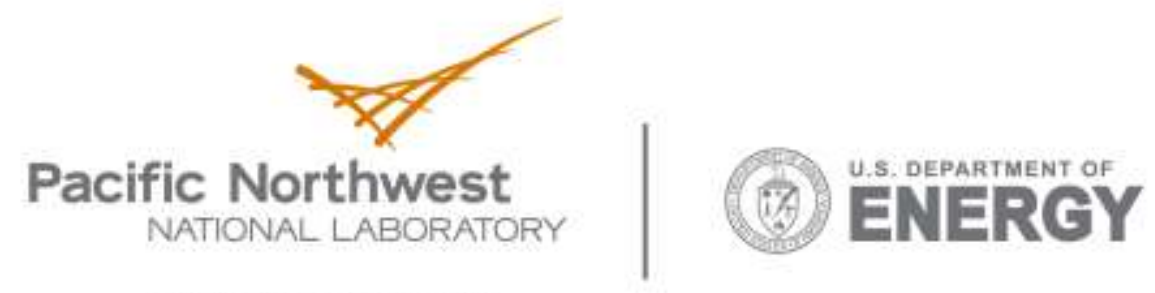

902 Battelle Boulevard

P.O. Box 999

Richland, WA 99352

1-888-375-PNNL (7665)

www.pnl.gov 